\title{
Prospek Pengembangan Metode Identifikasi Spesies Burung berdasarkan Spektrum Suara menggunakan Analisis Spektogram
}

\author{
Prospect of Development of Identification Method of Bird Species based on Sound \\ Spectrum using Spectrogram Analysis
}

\author{
Irwandi $^{1 *}$, Marwan', A. Hadi Mahmud ${ }^{1}$, dan Abdullah ${ }^{1}$ \\ Fakultas MIPA Universitas Syiah Kuala, Banda Aceh *penulis untuk korespondensi
}

\begin{abstract}
Bird species can be identified using bird's sound. Research about sound bird identification is lacking in Indonesia. This research is initial study to classify bird based on sound and its spectrum. The research was done in Laboratory of Animal Anatomy to record bird sample sound and Laboratory of Computation Physics for data analysis. This research used five recorded sound birds, i.e. Blue-Crowned (Loriculus galgulus), Greater Green (Chloropsis sonnerati), Black-Crested (Pycnonotus melanicterus), LongTailed (Lanius schach), and Asian Pied Starling (Sturnus contra). Identification of bird sound spectrum has been done using Fast Fourier Transform (FFT) method. Bird sounds and spectral that plotted in time-domain and in frequency-domain, were indicated unique pattern lead to bird identification method. The result showed that five birds recorded had different sound characteristics, both in time domain and sound spectrum frequency domain. The sound spectrum identification method can be used as initial step toward bird species classification called sono-taxonomy.
\end{abstract}

Key words: Sounds spectrum, FFT, sono-taxonomy

Diterima: 19 Mei 2004 disetujui: 14 Juni 2004

\section{Pendahuluan}

Selama ini usaha untuk identifikasi spesies burung dilakukan berdasarkan bentuk morfologinya (MacKinnon and Philips, 1993; O'Brien and Kinnaird. 1996) yaitu dilihat dari susunan morfologi dan anatominya. Selain itu klasifikasi makhluk hidup, juga dapat dilakukan berdasarkan komposisi kimia yang dikenal sebagai Chemotaxonomy. Namun, usaha ke arah klasifikasi berdasarkan identitas suara masih kurang dilakukan di Indonesia. Oleh karena itu pada penelitian ini dilakukan studi awal untuk melihat kemungkinan identifikasi serta klasifikasi burung berdasarkan spektrum suaranya.

Burung pada umumnya mengeluarkan suara dengan ciri yang khas, sehingga untuk mengenalinya dapat dilakukan dengan identifikasi suara. Banyak nama daerah untuk jenis burung tertentu diambil dari suaranya, misalnya kawau untuk burung kuau raja, dan keteran untuk perkutut (Soemarjoto dan Raharjo, 2000; Turut, 2000).

Untuk keperluan analisis spektogram perlu dilakukan perekaman dengan menggunakan 'tape recorders' (alat perekam) dengan sensor utama adalah mikrofon. Peralatan rekam yang digunakan harus diperhatikan beberapa karakteristik, seperti :

a. Frequency respose adalah kisaran perubahan (skala) amplitudo yang berhubungan dengan frekuensi (tertinggi hingga terendah) dalam hertz yang turut mempengaruhi jumlah desibel (dB).

b. Siqnal to noise ratio adalah rasio antara latar belakang suara gangguan (derau) yang terekam dengan sinyal 
yang masuk ke dalam alat perekam. Rasio yang baik berkisar 55-60 dB

c. Dynamic range adalah kisaran variasi amplitudo yang terdapat pada setiap alat perekam

d. Tape-speed menunjukkan kecepatan rekaman yang akan menentukan kualitas optimum hasil rekaman. (Cromer 1974; Wickstrom 1982; Lehner 1996; Ackerman 1998).

Visualisasi data suara burung dalam ranah waktu mampu memperlihatkan karakteristik, seperti adanya pola element (elemen), syllables (silabi: suku kata), dan Phrase (frase: ucapan). Untuk melakukan analisis secara lebih mendetail digunakan metode sonograf. Sonograf merupakan analisa spektrum frekuensi dengan memecah (membagi) suara menjadi unsur-unsur pokok frekuensi (Catchpole and Slater, 1995)

Spektrogram adalah metoda analisis suara pada komputer menjadi spektrum frekuensi melalui algoritma transformasi Fast Fourrier Transform (Transformasi Fourier Cepat). Dalam spektrogram hal pokok yang patut diingat adalah bahwa suara dengan volume tinggi akan muncul dengan kisaran frekuensi tinggi yang tampak pada sumbu y (Fitri, 2002).

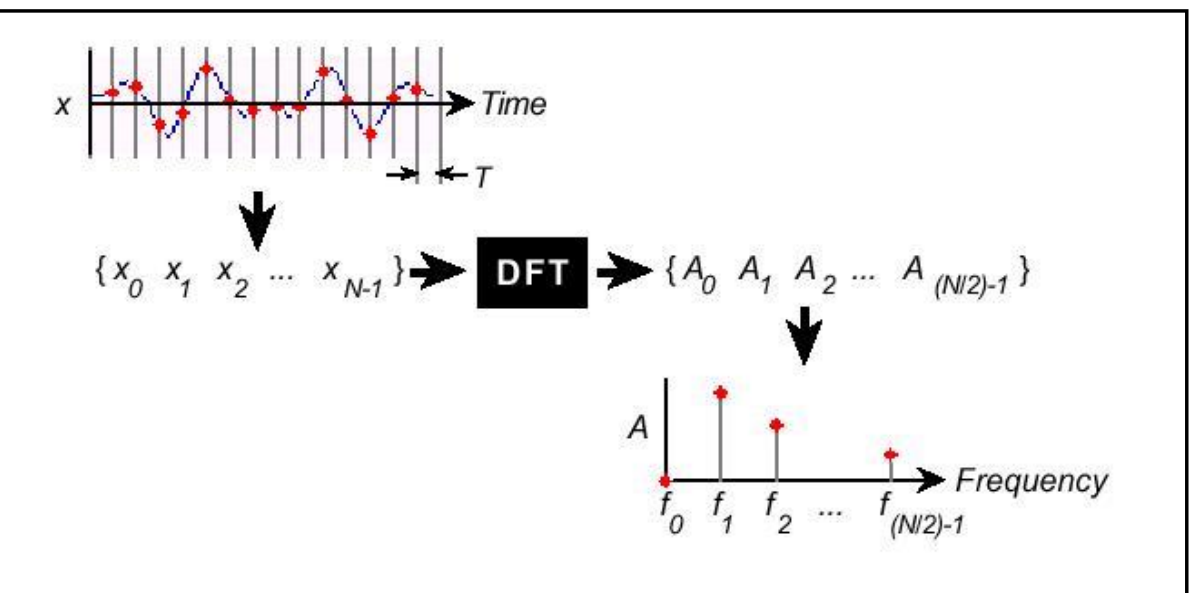

Gambar 1. Skema Transformasi Fourier Diskret (DFT) dari data ranah waktu ke data ranah frekuensi. $x_{0}, x_{1}, x_{2} \ldots x_{N-1}$ adalah data pengukuran dalam ranah waktu dengan selang sampling T. $A_{0}, A_{1}, A_{2} \ldots A_{(N / 2)-1}$ adalah data spektrum dalam ranah frekuensi $f_{0}, f_{1}, f_{2} \ldots f_{(N / 2)-1}$ yang diperoleh setelah melalui proses DFT (Donald, 1999)

Transformasi Fourier Cepat (Fast Fourier Transform) disingkat FFT merupakan pengembangan dari algoritma Transformasi Fourier Diskret (Discreet Fourier Transform) yang telah dipakai untuk analisis gelombang yang terjadi di alam (Brenner, 1998) gelombang pasang surut laut (Ariani, 1999), gelombang superposisi sinyal listrik yang secara umum diperlihatkan pada Gambar 1. (Capra, 1989). Transformasi Fourier Diskret merupakan bentuk diskrit dari integral Fourier transform (Vasely, 1994) sehingga memungkinkan untuk mengolah data diskret hasil rekaman tersimpan dalam komputer.

$$
F_{n}\left(f_{n}\right) \equiv \sum_{k=0}^{N-1} x_{k} e^{-2 \pi i k n / N}
$$

Keterangan: (Vasely, 1994)

$$
x_{k}=\text { data rekaman suara burung yang }
$$

indeks ke $k=1,2,3 \ldots . N$ 
$F_{n} \quad=$ Spektrum diskrit dengan domain frekuensi $f_{n}=\frac{n}{2 N \Delta t}$ (lihat Gambar 1)

$\Delta t=$ selang waktu pengambilan data sampling per second.

$\mathrm{N}=$ Jumlah pengambilan data

$\pi=3,14 \quad i=\sqrt{-1}$ (bilangan imaginer)

$e=2,718$ (eksponen alamiah)

Penelitian ini bertujuan untuk mendapatkan metode identifikasi dan klasifikasi spesies burung berdasarkan suara (sono-taksonomi).

\section{Metode Penelitian}

Penelitian ini dilakukan di Laboratorium Anatomi Hewan untuk proses perekaman suara burung. Pengolahan data dilakukan di Laboratorium Fisika Komputasi. Proses identifikasi dilakukan dalam beberapa tahapan yang secara umum dapat dilihat pada Gambar 2.

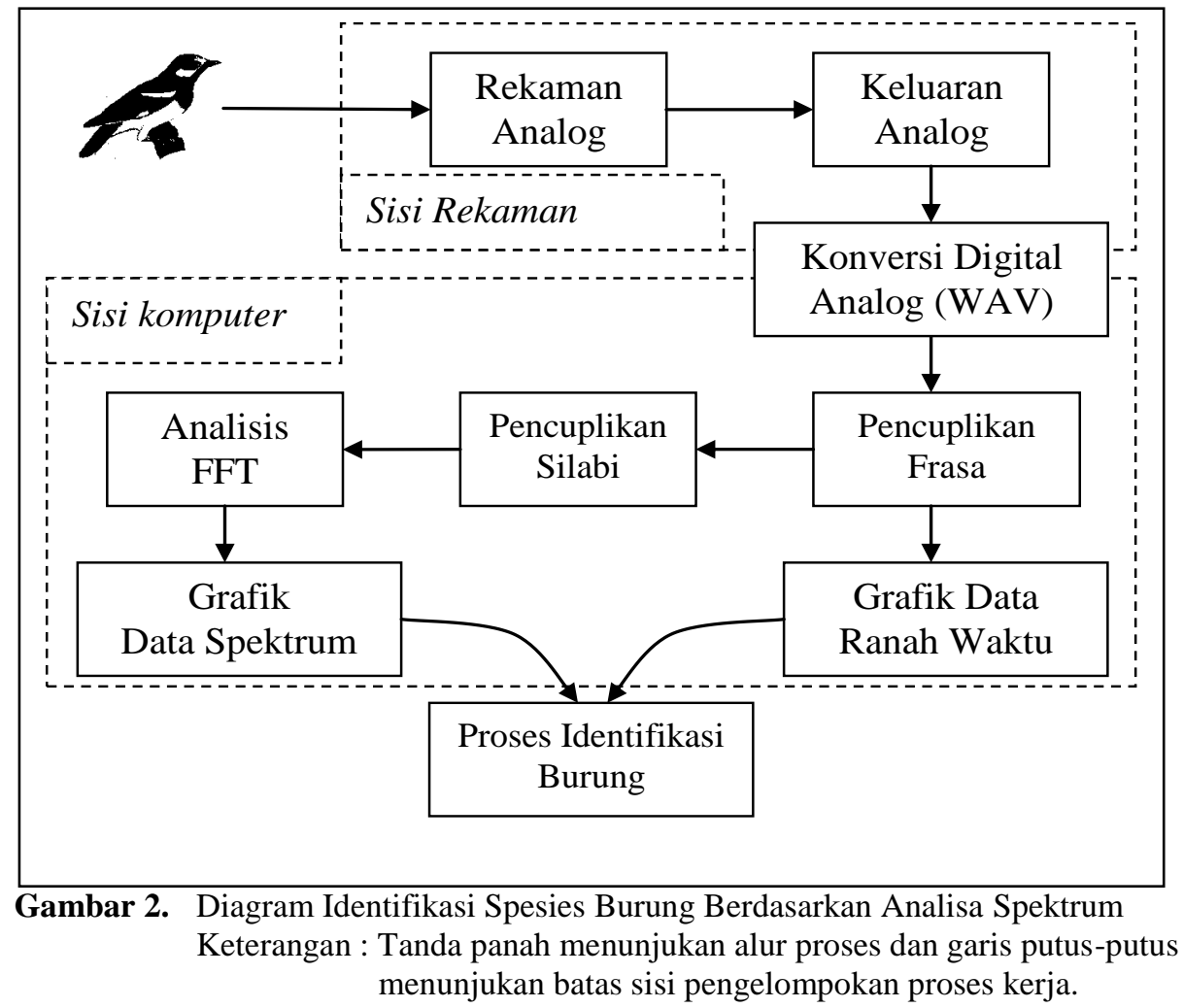

Pada penelitian ini disediakan lima jenis burung yang relatif mudah didapat seperti Serindit Melayu (Loriculus galgulus), CicaDaun Besar (Chloropsis sonnerati), Cucak Kuning (Pycnonotus melanicterus), Bentet Kelabu (Lanius schach), dan Jalak Suren (Sturnus contra). Proses perekaman analog dilakukan dengan menggunakan alat perekam dalam selang waktu tertentu sehingga terekam beberapa kali suara burung. Perekaman suara burung dilakukan pada pagi hari (07.00 - 10.00 WIB). Bila burungnya sulit mengeluarkan suara maka dilalukan Audio Playback yang berfungsi untuk menstimulasi burung untuk mendapatkan respon (suara). Audio Playback biasanya merupakan hasil rekaman suara burung yang di-replay untuk merangsang burung-burung sejenis atau berbeda jenis membalas kicauan rekaman suara burung (Fitri, 2002).

Data analog yang terdapat di alat perekam ditranfer ke komputer melalui jalur line in (jalur untuk memasukan sinyal) pada soundcard. Data yang ditransfer ke komputer dipilih saat burung mengeluarkan suaranya (pencuplikan sampling suara). Informasi suara 
tersebut diubah ke file dengan format WAV (Microsoft Waveform Audio Files) dengan bantuan perangkat lunak Microsoft Sound Recording.

Untuk memilih sinyal suara yang lebih baik dari file WAV tersebut dilakukan proses pencuplikan dengan menggunakan perangkat lunak SoundEditPro. Sinyal suara yang baik ialah yang relatif tidak mengandung derau (noise) dan suara yang dihasilkan cukup panjang untuk merepresentasikan satu buah frasa dari suara burung tersebut. Visualisasi cuplikan frasa suara tersebut mampu menggambarkan karakteristik suara dalam ranah waktu dengan terbentuk pola elemen, silabi, dan frasa.

Untuk melakukan proses analisis spektrogram dilakukan pencuplikan yang lebih kecil lagi supaya jumlah data tidak terlalu besar sehingga mempermudah proses FFT. Selain itu juga untuk memperoleh gelombang yang kelihatan kontinyu sehingga kemungkinan kesalahan karena derau dan perbedaan fase pada proses FFT dapat dikurangi. Untuk melakukan proses numerik FFT data suara tadi disimpan dalam format file text yang dapat dibaca sebagai nilai kuantitatif. Hasil proses FFT bila direpresentasikan dalam bentuk kuadratik menghasilkan spektrum dalam ranah frekuensi atau yang lebih dikenal sebagai spektrogram.

Berdasarkan informasi gambaran suara dalam ranah waktu dan spektrum dalam ranah ristiknya yang akan digunakan sebagai dasar untuk melakukan identifikasi burung.

\section{Hasil dan Pembahasan}

Pada penelitian ini digunakan lima individu yang mewakili lima spesies. Hasil pengambilan data suara burung dalam ranah waktu menunjukan adanya keteraturan pola elemen yang merupakan unit (satuan) suara terkecil.Kumpulan elemen tersebut membentuk silabi dengan pola susunan elemen yang berulang setiap silabi. Kumpulan beberapa silabi membentuk frasa (lihat Gambar 3).

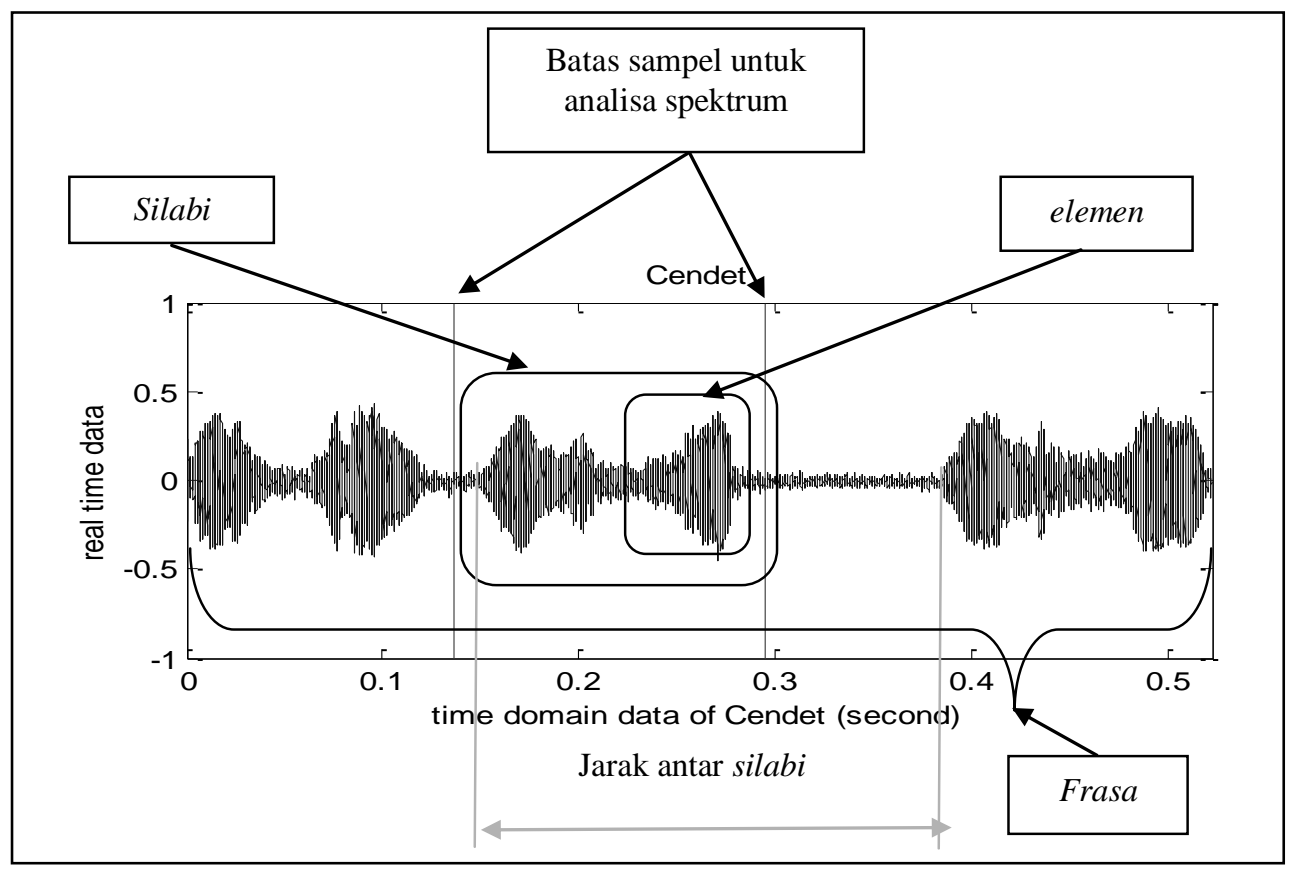

Gambar 3. Karakteristik pola suara sampel burung Bentet Kelabu (Lanius schach)

Data suara yang dihasilkan burung bukan merupakan superposisi komponen gelombang yang kontinyu, namun bersifat insidentil. Artinya antara satu suara dengan suara lainnya bisa muncul pada selang waktu yang berbeda yang mengakibatkan gelombang memiliki fase yang tidak sama. Hasil rekaman burung Bentet Kelabu (Gambar 3) memperlihatkan jarak antara silabi memiliki selang waktu yang berbeda. Karena proses FFT 
harus memenuhi kriteria gelombang yang kontinyu maka hanya digunakan sampling data dalam satu silabi. Penggunaan data suara satu silabi dengan harapan terjadi kontinyuitas gelombang karena diasumsikan satu silabi terbentuk pada satu proses pembangkitan gelombang oleh burung.

Data suara untuk cuplikan satu silabi dianalisa dengan FFT menghasilkan spektrum dalam domain frekuensi. Grafik ini terbentuk dari kuadrat nilai mutlak koefisien Fourier transform $\left|F_{n}\right|^{2}$ dalam ranah frekuensi. Pola spektrum cuplikan satu silabi pada Gambar 3 diperlihatkan pada Gambar 4. Berdasarkan kedua informasi, grafik gelombang suara dalam ranah waktu (Gambar 3) dan grafik spektrum dalam ranah frekuensi, dapat dipelajari ciri yang khas untuk setiap jenis burung, sehingga dapat dilakukan proses identifikasi burung berdasarkan suaranya.

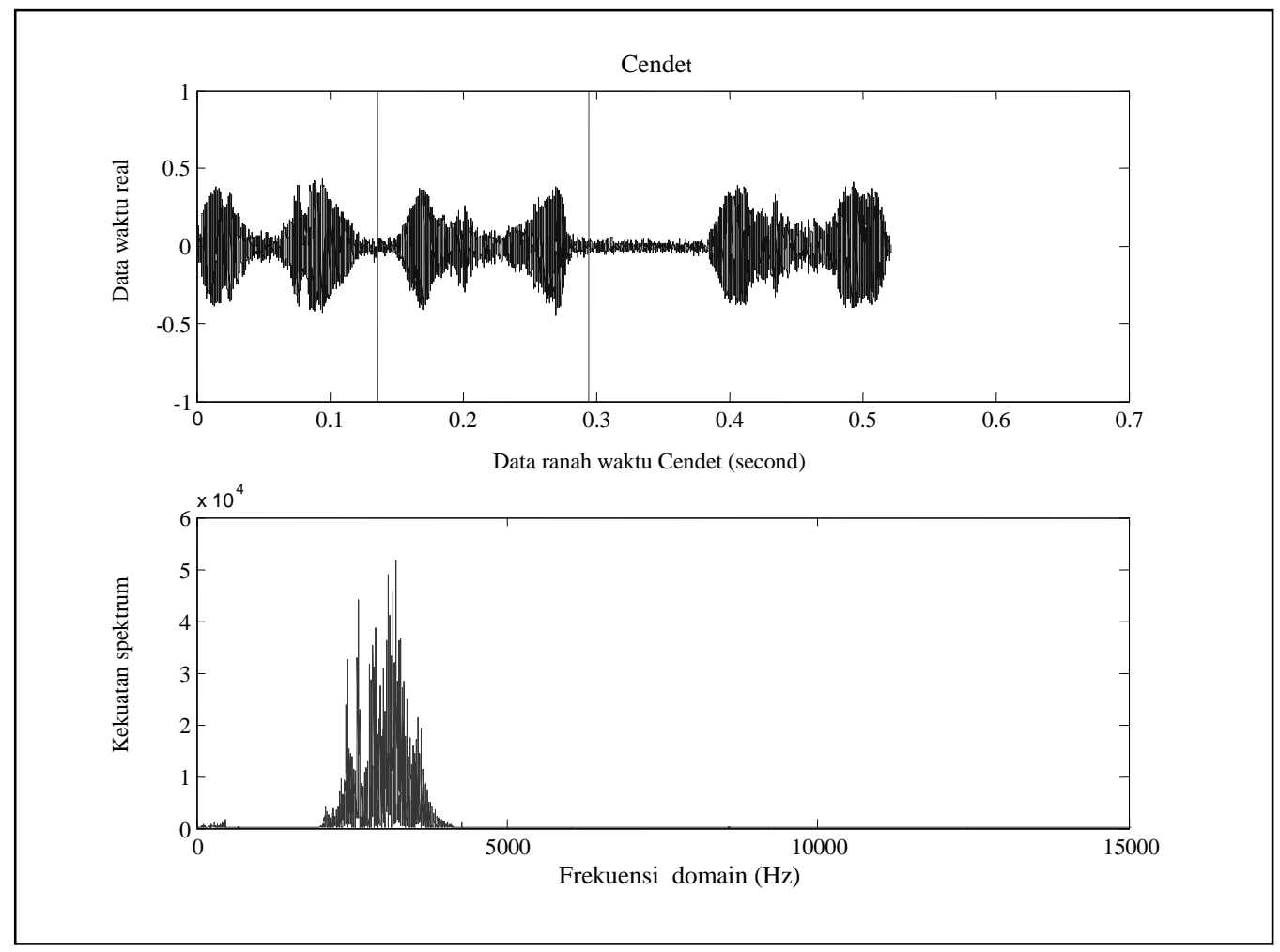

Gambar 4. Karakteristik Pola spektrum sampel burung Bentet Kelabu

Dari Gambar 3 dan 4 dapat dilakukan identifikasi bahwa burung Bentet kelabu (Lanius schach) memiliki jarak antar silabi tidak tetap, ada yang berjarak 0,2 detik dan 0,3 detik. Satu silabi memiliki dua elemen. Frekuensi maksimum $4000 \mathrm{~Hz}$ dan frekuensi dominan $3000 \mathrm{~Hz}$. Pola spektrum suara hanya memperlihatkan satu puncak spektrum pada frekuensi $3000 \mathrm{~Hz}$.

Bentet Kelabu memiliki ukuran tubuh 25 $\mathrm{cm}$, berwarna hitam, coklat, dan putih, berekor panjang. Dewasa: dahi, topeng dan ekor berwarna hitam. Sayap hitam dengan bintik putih, mahkota dan tengkuk abu-abu atau abu- abu hitam; punggung, tunggir dan sisi tubuh coklat kemerahan; dagu, tenggorokan, dada dan perut tengah putih. Luas warna hitam pada kepala dan punggung bervariasi, bergantung pada ras, individu dan umur. Bagi burung remaja warna lebih suram dengan garis pada sisi tubuh dan punggung, serta kepala dan tengkuk lebih abu-abu. Iris coklat, paruh dan kaki hitam. Penyebaran burung ini di Sumatera dan pulau sekitarnya dan umumnya dijumpai pada ketinggian $1600 \mathrm{~m}$

Sebagai perbandingan pada Gambar 5 diperlihatkan hasil rekaman dan spektrum untuk burung Jalak Suren (Sturnus contra). 
Jalak Suren memiliki jarak antar silabi selama 0,4 detik dan silabi memiliki satu elemen. Frekuensi maksimum $4000 \mathrm{~Hz}$ dan frekuensi dominan $3000 \mathrm{~Hz}$. Pola spektrum suara membentuk tiga puncak spektrum dominan pada frekuensi $1000 \mathrm{~Hz}, 3000 \mathrm{~Hz}$, dan 5000 Hz.

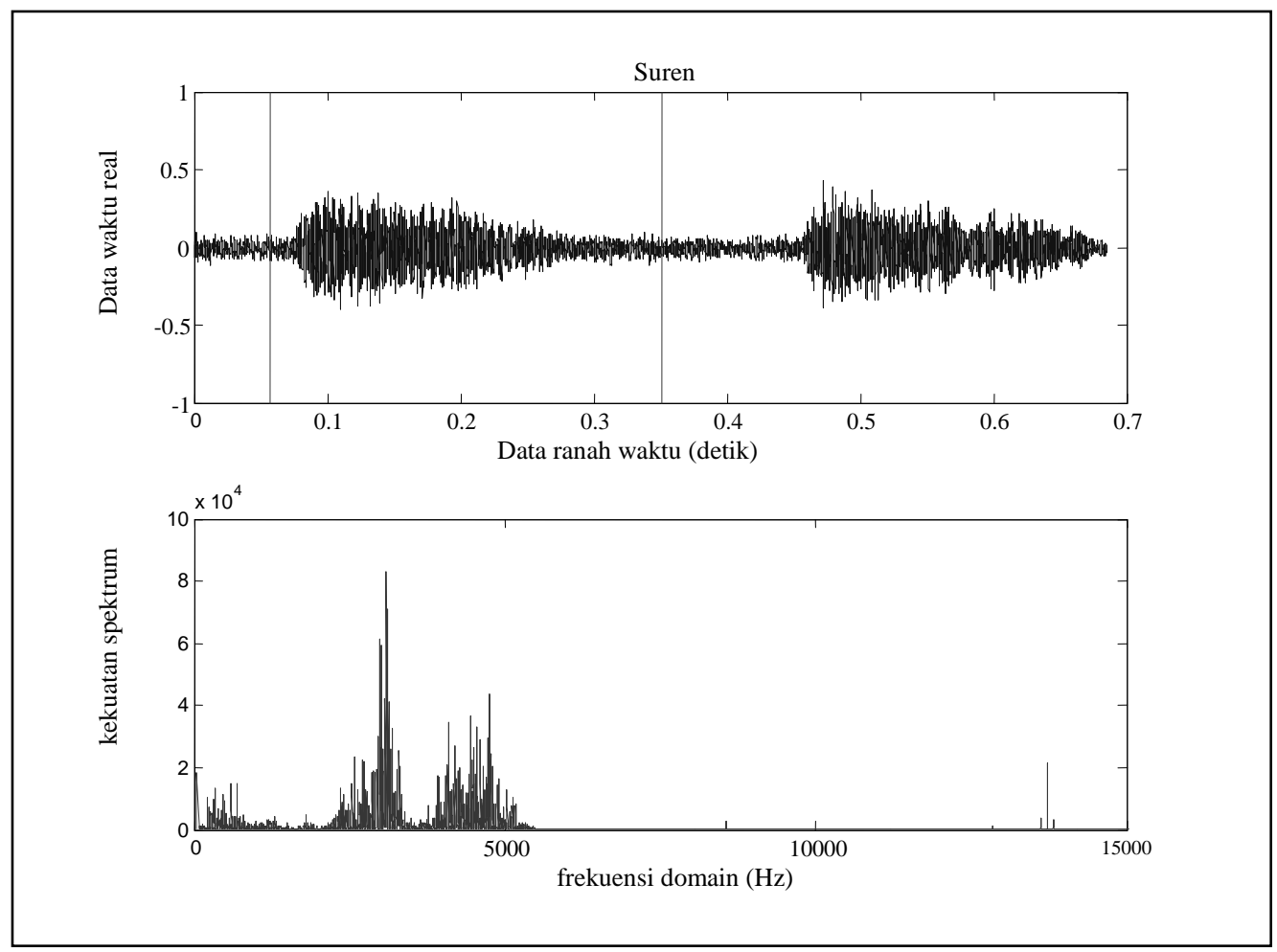

Gambar 5. Karakteristik pola suara dan spektrum sampel burung Jalak Suren

Pada penelitian ini telah dilakukan pengamatan yang sama untuk burung Serindit Melayu, Cica-Daun besar, dan Cucak Emas. Burung ini memiliki ciri morfologi ukuran tubuh $24 \mathrm{~cm}$, berwarna hitam dan putih. Dahi, pipi, garis sayap, tunggir dan perut putih, dada, tenggorokan, dan tubuh bagian atas hitam (coklat pada remaja). Iris abu-abu, kulit tanpa bulu di sekitar mata berwarna jingga, paruh merah dengan ujung putih, kaki kuning. Penyebarannya di Sumatera dan pulau sekitar. Masing-masing jenis burung memiliki keunikan parameter suara tersendiri yang diringkas dalam Tabel 1.

Dari kelima sampel burung tersebut frekuensi maksimum dihasilkan oleh burung Sigeundét (Loriculus galgulus) sebesar 6500 Hz. Burung yang memiliki satu elemen dalam satu silabi selain Sigeundét adalah Kutilang Emas, dan Suren. Sedangkan Murai Daun dan
Cendet paket suaranya memiliki dua elemen dalam satu silabi.

\section{Kesimpulan}

Gambaran data suara burung dalam ranah waktu dapat mengidentifikasi pola pembentukan elemen, silabi, dan frasa. Sedangkan gambaran spektrum dalam ranah frekuensi dapat mengidentifikasi frekuensi dominan, frekuensi maksimum, dan jumlah puncak frekuensi. Masing-masing individu yang mewakili spesies dapat diidentifikasi dengan melihat beberapa parameter suara yang dihasilkannya. Setelah dilakukan penelitian ini ternyata prospek pengembangan metode identifikasi spesies burung berdasarkan spektrum suara melalui analisis spektogram memiliki kemungkinan untuk dikembangkan pada tahap lebih lanjut. 
Irwandi, $d k k$.

Tabel 1. Parameter karakteritik yang mengIdentifikasi suara 5 jenis burung

\begin{tabular}{cllccccc}
\hline \hline No & $\begin{array}{l}\text { Nama Daerah Aceh/ } \\
\text { Nama Indonesia }\end{array}$ & $\begin{array}{l}\text { Nama Inggris/ } \\
\text { Nama Latin }\end{array}$ & $\begin{array}{c}\text { Frekuensi } \\
\text { dominan }\end{array}$ & $\begin{array}{c}\text { Frekuensi } \\
\text { maksimum }\end{array}$ & $\begin{array}{c}\text { Jml puncak } \\
\text { frekuensi }\end{array}$ & $\begin{array}{c}\text { Jarak antar } \\
\text { silabi }\end{array}$ & $\begin{array}{c}\text { Jumlah } \\
\text { elemen }\end{array}$ \\
\hline \hline 1 & $\begin{array}{l}\text { Cendet/ } \\
\text { Bentet Kelabu }\end{array}$ & $\begin{array}{l}\text { Long-tailed } \\
\text { Lanius schach } \\
\text { Suren/ }\end{array}$ & $3000 \mathrm{~Hz}$ & $4000 \mathrm{~Hz}$ & 1 & $0,2-0,3 \mathrm{dtk}$ & 2 \\
& $\begin{array}{l}\text { Jaian Pied } \\
\text { Jalak Suren }\end{array}$ & $3000 \mathrm{~Hz}$ & $4000 \mathrm{~Hz}$ & 3 & $0,4 \mathrm{dtk}$ & 1 \\
3 & $\begin{array}{l}\text { Starling } \\
\text { Sturnus contra } \\
\text { Serindit Melayu }\end{array}$ & $\begin{array}{l}\text { Blue-crowned } \\
\text { Loriculus } \\
\text { galgulus } \\
\text { Greater green } \\
\text { Chioropsis }\end{array}$ & $2500 \mathrm{~Hz}$ & $6500 \mathrm{~Hz}$ & 3 & $0,1 \mathrm{dtk}$ & 1 \\
4 & $\begin{array}{l}\text { Murai Daun/ } \\
\text { Cica-Daun Besar }\end{array}$ & $\begin{array}{l}\text { sonnerati } \\
\text { Black-crested } \\
\text { Pycnontus } \\
\text { melanicterus }\end{array}$ & $2750 \mathrm{~Hz}$ & $3000 \mathrm{~Hz}$ & 2 & $0,3 \mathrm{dtk}$ & 1 \\
5 & $\begin{array}{l}\text { Kutilang Emas/ } \\
\text { Cucak Kuning }\end{array}$ & & 2 & $0,2 \mathrm{dtk}$ & 2 \\
\hline \hline
\end{tabular}

\section{Saran}

Penelitian ini merupakan studi awal dengan menggunakan jumlah sampel burung yang relatif sedikit, sehingga perlu dikembangkan lagi dengan variasi jumlah spesies, umur, jenis kelamin, waktu rekaman, dan beberapa parameter lain, sehingga diharapkan dapat ditemukan bentuk klasifikasi burung berdasarkan suaranya (sono-taksonomi).

Keterbatasan dalam penelitian ini adalah perekaman suara burung belum mempertimbangkan faktor perilakunya (perilaku kawin, makan, atau pertahanan wilayah).

\section{Ucapan Terima Kasih}

Ucapan terima kasih disampaikan kepada Proyek Pengkajian dan Penelitian Ilmu Pengetahuan dan Teknologi, Direktorat Jenderal Pendidikan Nasional, yang telah membiayai penelitian ini sesuai dengan Surat Perjanjian Pelaksanaan Penelitian Dasar, Nomor: 011/P2IPT/DPPM/IV/2002 tanggal 9 April 2002.

\section{Daftar Pustaka}

Ackerman, E. 1998. Biophysical Science. PrenticeHall, Inc. Englewood Cliffs, New Jersey.

Ariani, Y. 1999. Discrete Fourier Transform dari Data Ketinggian Pasang Surut Laut (Tide Height) di Perairan Aceh, FMIPA Unsyiah.

Capra, C.S. and Canale. 1989. Metode Numerik, Erlangga, Jakarta.

Catchpole, C.K. and Slater, P.J.B. 1995. Bird song: biological themes and variations. Cambridge Univ. Press, Cambridge.

Cromer, A.H. 1974. Physics for the Life Science. $2^{\text {nd }}$ Edition. Mc Graw-Hill, Inc. Northeastern University.

Donald, B.W. Example of Fourier Transfom, http://www4.ncsu.edu/ eos/info/mat310_info/fourier_example,ht ml. (12 Februari 1999).

Fitri, L.L. 2002. Panduan Singkat Perekaman dan Analisa Suara burung, Jurusan Biologi, FMIPA ITB.

Lehner, P.N. 1996. Handbook of ethological methods. $2^{\text {nd }}$ Edition Cambride Univ. Press, Cambridge.

MacKinnon, J. and Philips, K. 1993. A field guide to the birds of Borneo, Sumatra, Java, and Bali. Oxford Unversity Press, Oxford. 
Marwan, Mahmud, A. H. dan Irwandi. 2002. Upaya Pemanfaatan Metode Klasifikasi Spesies Burung Berdasarkan Spektrum Suara Melalui Analisis Proses Diskret Fourier Transform. Laporan Penelitian Dasar. Banda Aceh.

O'Brien, T. and Kinnaird, M.F. 1996. Birds and mammals of the Bukit Barisan Selatan National Park, Sumatra, Indonesia, Indonesia. Oryx 30(3):207-217.

Soemarjoto, R. dan Raharjo, R.I.B. 2000. Pedoman Lomba Perkutut, Derkuku dan burung berkicau. Penebar Swadaya, Depok.
Turut, R. 2000. Sukses dalam kontes burung berkicau. Penebar Swadaya, Depok.

Vasely, F.T. 1994. Computational Physics An Introduction. Plenum Press. New York.

Wickstrom, D.C. 1992. Factors to consider in recording avian songs. In Acoustic communication in birds. Vol I. Academic Press, New York, hal. 1 - 52. 